\title{
Source tags
}

\section{Angelika Kiss*}

\begin{abstract}
In this paper I argue that when question tags such as huh? in (North American) English, eh? in Italian and $m i$ ? in Hungarian follow a declarative anchor, they are subject to special contextual constraints. They convey that the speaker perceives the addressee to be a source for $p$, the proposition conveyed by the anchor, and in addition, the presupposition that the speaker herself is a source for the addressee being a source for $p$.
\end{abstract}

Keywords. tag questions; huh?; eh?; mi?; commitment; presupposition; sourcehood; evidentiality strategy; conversational scoreboard; English; Italian; Hungarian

1. Introduction. Tag questions express speaker bias and elicit confirmation or acknowledgment from the addressee (Ladd 1981; Asher \& Reese 2007; Farkas \& Bruce 2010; Malamud \& Stephenson 2015; Farkas \& Roelofsen 2017). In English, a speaker who chooses to pronounce a tag question like (1-a) with a falling intonation on the tag, expresses commitment to the proposition conveyed by the anchor, that '2020 was a tough year' and may use the reverse polarity tag wasn't it? to elicit participation from the addressee. On the other hand, a tag question like (1-b) may be used in a situation in which the speaker has doubts about whether the vaccine in question is safe.

\section{(1) a. 2020 was a tough year, wasn't it?}

b. The vaccine's safe, right?

Both utterances are formally complex, as their anchor is a declarative clause and their tags are arguably reduced interrogative clauses. Accordingly, their meaning consists of an assertive and an inquisitive component. Once the addressee acknowledges an utterance like (1-a) or (1-b), the proposition conveyed by the declarative anchor becomes part of the common ground.

The above basic description characterizes question tags found in many languages, and may characterize more than one question tag within the same language, although individual tags within a language may have further specific contextual restrictions. The following examples are from Italian and Hungarian.
a. Il vaccino è sicuro, vero? / no? / o sbaglio? (Italian)
the vaccine is safe true no or be.wrong.PRES.1SG
b. Az oltás biztonságos, ugye? / (vagy) nem? (Hungarian) the vaccine safe right or not 'The vaccine is safe, right?'

Besides these basic, confirmation/acknowledgment-eliciting question tags, we also find another kind in these three languages, shown in (3), that has received far less attention in the linguistic literature.

\footnotetext{
* Thanks to Gábor Alberti, Liz Coppock, Julianne Doner, Beáta Gyuris, Michela Ippolito, Ruth Maddeaux, Sophia Malamud, Olivia Marasco, Cecília Molnár, Natalia Rinaldi, Heather Stephens, Timothy Gadanidis, Guillaume Thomas, Maxime Tulling, Fiona Wilson, the SemPrag reading group at the University of Toronto, and the audiences of the 14th International Conference on the Structure of Hungarian and of Sensus 1. Author: Angelika Kiss, University of Toronto (angelika.kiss@mail.utoronto.ca).
} 
(3) a. 2020 was a tough year, huh?

b. 2020 è stato un anno difficile, eh? (Italian)

c. 2020 nehéz egy év volt, mi? (Hungarian)

The tag questions in (3), similarly to the previous examples, also convey a speaker's bias and elicit confirmation from the addressee, but they are subject to some additional contextual restrictions. I claim that the invariable tags huh?, eh? and $m i$ ?, uttered with a rising intonation, convey that i) the speaker takes the addressee to believe that the proposition conveyed by the anchor is true, and this belief of the addressee is independent of anyone else's commitment; ii) and that the speaker believes, independently of anyone else's commitment, that this is the case. I argue that ii) is a pragmatic presupposition, that is, information that the speaker takes for granted (Stalnaker 1974).

The paper is organized as follows. In section 2, I introduce Gunlogson's (2008) distinction of dependent and independent commitment/sourcehood, which I argue is necessary to characterize the bias these tags introduce. Section 3 characterizes the bias of source tags by showing their acceptability pattern in a variety of contexts. In section 4 , I model the effect of source tags on the context using a conversational scoreboard. Finally, I raise some open issues in section 5, which is followed by the conclusion.

2. Dependent and independent commitments. Gunlogson (2008) introduced the notion of independent commitment or sourcehood, which is of crucial importance when describing tags like $h u h$ ?, eh? and $m i$ ?. When a speaker $x$ makes an assertion with the propositional content $p$, she commits herself to the truth of $p$. This means that $x$ can be held accountable for it in the future, when committing to some proposition $q$ that is (contextually or logically) incompatible with $p$. By default, when making a public commitment in the form of an unadorned assertion as in (4), the speaker is taken to have enough evidence for doing so. This truth is captured by Grice's Maxim of Quality (Grice 1975).

\section{(4) The vaccine is safe.}

A speaker who makes the claim in (4) will be taken as someone who is convinced about the truth of the proposition $p=$ 'the vaccine is safe', and is convinced independently of the commitment of other conversational agents' commitments. In Gunlogson's terms, in this case the speaker of (4) is a source for $p$ in dialogue $d$. Gunlogson contrasts independent commitment or sourcehood with dependent or contingent commitments. If a speaker $x$ in dialogue $d$ commits to $p$ based solely on the grounds that another speaker $y$ made a commitment to $p$, then speaker $x$ is only dependently committed to $p$. We can see this is the case because if $y$ retracts their commitment, $x$ will do the same by default.

(5) a. A: The server's down.

b. B: Oh. (I didn't know that.) (Gunlogson 2008; (25))

Speaker A in the mini-dialogue (5) is a source for the proposition that 'the server is down'. Speaker B indicated that this piece of information was new to him by uttering oh (Gunlogson 2008; Kraus 2019), but the follow-up ("I didn't know that") signals acceptance. Speaker B can therefore be taken as committed to $p$ as well. However, if after the conversation in (5), A retracts their commitment to $p$ by saying "No, I was wrong, it's working!", speaker B would no longer be taken to be committed to $p$. 
In addition to the distinction between dependent and independent commitments, I also assume that cases of non-verbally publicized beliefs commit the speaker the same way as verbally publicized ones. This is permitted by Gunlogson's (2008) definition of commitments shown in (6) which is also assumed in this paper.

(6) Status of a proposition $\phi$ with respect to a discourse context $\mathrm{C}$ :

$\phi$ is a commitment in $\mathrm{C}$ of an agent $\alpha$ iff $\mathrm{CS}_{\alpha}$ is not empty and $\mathrm{CS}_{\alpha} \subseteq \phi$. (Gunlogson $2008 ; 10)$

3. The bias conveyed by huh?, eh? and mi?. Tag questions with huh?, eh?, and mi? are biased, which means that they express more than just an inquiry with the purpose of filling in an informational gap. Even though they are not polar questions, they have a sentence radical (referred to as their anchor), and therefore they are comparable to other expressions with a sentence radical, such as assertions or polar questions.

Tag questions are similar to assertions, in that they both commit their speaker to the truth of $p$, the proposition conveyed by the sentence radical (or the highlighted alternative (Farkas $\&$ Roelofsen 2017)). But at the same time, tag questions may weaken the speaker's commitment to $p$. Tag questions are also similar to polar questions, in that they explicitly raise the issue of whether $p$ is true (Farkas \& Bruce 2010; Farkas \& Roelofsen 2017). However, unlike polar questions, the two alternatives of a tag question, $p$ and $\neg p$ are not represented as equivalently possible answers, due to the speaker's bias towards the truth of $p$.

Tag questions, despite raising an issue, are unacceptable in contexts where the speaker is, or is supposed to be, unbiased (Gunlogson 2003). An example of this is the context of a courtroom hearing. Examples (8) and (9) are the Italian and Hungarian equivalents of example $(7)^{1}$.

(7) a. Are you a member of the Communist Party?

b. You are a member of the Communist Party, \#aren't you? / \#huh?

(8) a. Lei è membro del Partito Comunista? (Italian)

b. Lei è membro del Partito Comunista, \#no? / \#eh?

(9) a. Ön tagja a Kommunista Pártnak? (Hungarian)

b. Ön tagja a Kommunista Pártnak, \#ugye? / \#mi?

While genuine polar questions like the a. examples are felicitous in such a context, any tag questions are unacceptable. However, there is more to say about the nature of the speaker bias expressed by huh?, eh? and $m i$ ?, as there are contexts that separate them from other tags. Consider (10), where B is somewhat uncertain about whether the vaccine is safe. ${ }^{2}$

(10) Context: A is a doctor, and B is A's patient.

a. B: The vaccine's safe, isn't it? / \#huh?

b. B: Il vaccino è sicuro, no? / \#eh? (Italian)

\footnotetext{
${ }^{1}$ In all subsequent triplets of examples, the translation of the Italian and Hungarian sentences is the English sentence itself.

2 The arrows ( $\uparrow$ and $\downarrow$ ) mark rising and falling intonation respectively, and are used whenever a tag can be pronounced otherwise and it is relevant for the given example that they have the intonation as marked by the arrow. In the case of the English reverse polarity tag question, rising intonation indicates less certainty than falling intonation (Reese 2007; Farkas \& Roelofsen 2017).
} 


\section{c. B: Az oltás biztonságos, ugye? / \#mi? (Hungarian)}

The examples in (10) show that while tag questions like the reverse polarity tag question in English (Malamud \& Stephenson 2015), no? in Italian (Servidio 2014) and ugye? in Hungarian (Gyuris 2009; Molnár 2018, 2019) allow some degree of uncertainty, huh?, eh? and mi? do not. In order to understand what the content of the bias is, it is necessary to look at what bias is attributed to the addressee when using these tags.

3.1. AdDRESSEE BIAS. I claim that source tags attribute a bias to the addressee. More specifically, utterances like (11) express the speaker's belief that the addressee believes that $p=$ '2020 was a tough year'.
a. 2020 was a tough year, huh?
b. 2020 è stato un anno difficile, eh? (Italian)
c. 2020 nehéz egy év volt, mi? (Hungarian)

In addition to signalling that the speaker believes that the addressee believes that 2020 was a tough year, these utterances also convey that this belief of the addressee does not depend on anyone else's commitment but is an independently held commitment of the addressee. In the following section, I look at adversative contexts which require the addressee and the speaker to be committed to the same proposition but of the opposite polarity, as well as predicates of personal taste, following Farkas \& Roelofsen (2012) and Malamud \& Stephenson (2015), which are methodologically useful in characterizing bias profiles in terms of dependent and independent commitments.

3.1.1. AdVERSATIVE CONTEXTS. Adversative contexts arise whenever there is a crisis in conversation due to incompatible commitments (Farkas \& Bruce 2010). If speaker A commits to $p$, and speaker B believes that $\neg p$ is the case (whether or not speaker $\mathrm{A}$ is aware of speaker B's belief), B can signal this adversativity by employing biased questions dedicated to such a purpose, such as negative polar questions (Ladd 1981; Büring \& Gunlogson 2000; Romero \& Han 2004), echo declarative questions (Poschmann 2008; Kiss 2020), or negative wh-constructions (Cheung 2009; Kiss 2017). In addition, the adversativity of these utterances can also be conveyed or reinforced by discourse particles (Egg 2013; Giorgi 2018; Eckardt $\&$ Yu 2020) and gestures (Ippolito 2019). Consider example (12), where the speaker has the evidential bias that Mary bought a red dress, but given the evidence found in the context, the addressee can no longer be taken to be committed to this fact. The speaker of (12-a) marks adversativity with the discourse particle $m a$.

(12) Context: Mary calls me on the phone and tells me that she has a new red dress to wear at tonight's party. When I meet her at the party, I see that she has a blue dress. I'm surprised and say:

\section{a. Ma non era rosso? (Italian) 'But wasn't it red?'}

(Giorgi 2018; (1))

In (13), the message conveyed by (12-a) is paraphrased as a tag question with a declarative anchor. While no? is available here as a tag, the source tag $e h$ ? is excluded, and the same contrast holds in their English and Hungarian equivalents.

(13) a. But you bought a red dress, didn't you?^/ \#huh? 
b. Ma tu hai comprato un vestito rosso, no? / \#eh? (Italian)

c. Dehát te egy piros ruhát vettél, nem? / \#mi? (Hungarian)

Based on the fact that the addressee is wearing a blue dress, there is reason for the speaker to doubt whether the addressee has bought a red dress at all. This supports the claim that source tags are felicitous when the speaker perceives addressee as being committed to the proposition conveyed by the anchor, $p=$ 'you bought a red dress'.

3.1.2. PREDICATES OF PERSONAL TASTE. In addition to the contextual restriction that the addressee cannot have a contrary propositional attitude towards $p$, propositions containing predicates of personal taste suggest that the addressee also must be independently committed to $p$.

According to Gunlogson (2008), dependent and independent commitments are locally determined. In conversation (5), one speaker presents herself as a source for $p$, and the other one makes a dependent/contingent commitment to $p$. Speaker B's commitment depends on speaker A's commitment, but this dependence only holds only for as long as the present dialogue $(d)$ lasts. If B treats $\mathrm{A}$ as a reliable source and genuinely believes $p$ to be true based on A's report alone, it can become an independent commitment of B's. This means that in a later dialogue $d^{\prime}$ with a third speaker $\mathrm{C}, \mathrm{B}$ can present himself as a source for $p$.

Predicates of personal taste (taste predicates, for short) are a useful tool in examining whether a certain commitment is dependent or independent, because the only way to independently commit to a proposition involving a taste predicate is by direct evidence. In a context like (14), in which the speaker perceives the addressee to be independently committed to $p=$ 'the ice-cream is tasty', source tags are felicitous.

(14) Context: A and B taste ice-cream X for the first time. Both enjoy it and can tell the same about each other, too. A to B:
a. It's tasty, isn't it? / huh?
b. È buono, no? / eh? (Italian)
c. Finom, ugye? / mi? (Hungarian)

However, if we modify the context in (14) so that the addressee does not have access to the taste of the ice-cream in question, source tags become unavailable.

(15) Context: A and B are waiting in line to taste ice-cream $X$ for the first time. A receives her ice-cream first, tastes it, and clearly likes it very much. B, who has not tried the ice-cream yet, can tell that A likes it. A to B:

a. It's tasty, ?isn't it? / \#huh?

b. È buono, \#no? / \#eh? (Italian)

c. Finom, \#ugye? / \#mi? (Hungarian)

The unacceptability of source tags in a context like (15) persists even if B happens to fully trust $\mathrm{A}$ as a source in matters of taste. If $\mathrm{B}$ commits to $p=$ 'ice-cream $\mathrm{X}$ is tasty' on the grounds that $\mathrm{A}$, whom he trusts in matters of taste, is also committed to $p$ (by presenting herself as enjoying the taste), then B's commitment can be at most a dependent commitment, given the fact that B has never tried the ice-cream before. The fact that source tags are infelicitous in such a case is evidence that B's dependent commitment is not enough for source tags to be used.

There is another relevant way to modify the context in (14): so that only the addressee has tasted the ice-cream. In this case, source tags are still acceptable, although acceptability 
judgments seem to be less straightforward as compared to example (14), where both speakers have tasted ice-cream $\mathrm{X}$.

(16) Context: A and B are waiting in line to taste ice-cream $\mathrm{X}$ which they have never tried before. $\mathrm{B}$ receives his ice-cream first, he tastes it, and clearly likes it very much, which A can also tell. A to B:

a. It's tasty, is it? / ?isn't it? / ?huh?

b. È buono, sì? / no? / ?eh? (Italian)

c. Finom, ugye? / ?mi? (Hungarian)

In a context like (16), the speaker (A) perceives the addressee (B) as enjoying ice-cream X, therefore A takes $\mathrm{B}$ to be independently committed to $p=$ 'ice-cream $\mathrm{X}$ is tasty'. This observation itself is an independent commitment of $\mathrm{A}$, given that A directly perceived the event. This context favors question tags that signal that the addressee has a higher epistemic authority than the speaker, such as the English same polarity tag is it?, sì? 'yes?' in Italian, and potentially vagy nem? 'or not?' in Hungarian. However, the contextual restrictions on source tags proposed in this paper predict that this context would also license source tags as in (14).

While native speakers considered source tags to be generally acceptable in (16), they gave more variable judgments to (16) than to (14). This can be explained as follows. Any kind of commitment is made on some ground, and arguably, sourcehood requires more solid grounds than dependent commitment, which are based on someone else's report. If source tags really need the speaker to be a source for the addressee's independent commitment to $p$, as is claimed here, then we expect source tags to be better in contexts where the speaker has more solid grounds based on which this independent commitment can be made. The contexts in (14) and (16) form a minimal pair in this respect: having direct access to the taste of ice-cream X constitutes stronger grounds for attributing any opinion of ice-cream $\mathrm{X}$ to someone else than without having access to its taste.

3.2. SPEAKER PRESUPPOSITION. I argued in the previous section that the speaker must perceive the addressee as being independently committed to $p$ in order to use source tags. In addition to that, source tags also convey that the speaker is a source for the fact that the addressee is a source for $p$. First, I show, by constructing different contexts, that a speaker who uses a source tag cannot be unbiased regarding the addressee's sourcehood, and that not even a dependent speaker commitment is enough to license a source tag. I then demonstrate that the speaker's commitment is a pragmatic presupposition (Stalnaker 1974).

Consider example (17), where the speaker is not committed to $q=$ 'the addressee is independently committed to $p$ '.

(17) Context: A and B meet near an ice-cream place where they sell ice-cream X. Both A and $\mathrm{B}$ have tasted ice-cream $\mathrm{X}$ before and both of them liked it, but they do not know this of each other. A points to ice-cream $\mathrm{X}$ and says to $\mathrm{B}$ :
a. Tasty, \#isn't it? / \#huh?
b. È buono, \#no? / \#eh? (Italian)
c. Finom, \#ugye? / \#mi? (Hungarian)

As expected, source tags in such an unbiased context are just as unacceptable as any other tag. I now turn to the question of whether it is enough for the speaker to be only dependently 
committed to the fact that the addressee is a source for $p$. Since the speaker's commitment is about someone else's commitment, it cannot be tested by taste predicates. But manipulating the above ice-cream contexts can show indirectly that source tags do indeed prefer contexts in which the speaker presents herself as a source for the fact that the addressee is a source for $p$.

First, let me acknowledge that the fact that the speaker bases their commitment on someone else's commitment may seem at first sight to be a dependent commitment like B's commitment in (5). However, I argue against this conclusion. In (5), B commits to 'the server is down', which is a commitment based on someone else's commitment, which makes it dependent. Speaker commitments that are signaled by source tags, however, are commitments about someone else's commitment, which is a different case. In the former case, the other interlocutor's commitment serves as the grounds for the dependent commitment, while in the case of source tags, the grounds for the speaker commitment originates from the speaker, not from someone else. The peculiarity is that the content of the commitment is indeed about someone else's commitment. ${ }^{3}$

Consider the situation in (18), in which the speaker has been informed about the addressee's experience with ice-cream X through someone else's report. Based on the proposal made in this paper, this context should not license source tags, however, they been judged acceptable by some speakers in English and Hungarian, and its acceptability in Italian is questionable.

Context: B and $\mathrm{C}$ have tasted ice-cream $\mathrm{X}$, and B found it very tasty. They meet with $\mathrm{A}$, who has never tasted ice-cream $\mathrm{X}$, and $\mathrm{C}$ tells $\mathrm{A}$ that $\mathrm{B}$ liked it. A to B:

a. It's tasty, is it? / isn't it? / \%huh?

b. È buono, sì? / no? / ?eh? (Italian)

c. Finom, vagy nem? / ugye? / \%mi? (Hungarian)

The fact that source tags are licensed here can be explained as follows. Gunlogson (2008) claims that dependent commitments are locally determined, that is, the dependent nature of the commitment holds no longer than the given discourse. But there is no clear boundary between being dependently and independently committed to a proposition: nothing prevents the speaker from internalizing the belief that $\mathrm{A}$ likes ice-cream $\mathrm{X}$ between two conversational turns; $\mathrm{A}$ thus could have become a source for $q=$ ' $\mathrm{B}$ is a source for $p$ (where $p=$ 'ice-cream $\mathrm{X}$ is tasty') right before uttering (18-a)-(18-b).

There is another way to reveal what kind of meaning this speaker commitment could be, namely by looking at what happens to the speaker's commitment to $q$ if the addressee accepts (as opposed to rejecting) the utterance with the source tag. Consider again context (14), repeated below in (19), together with a confirmative and a negative answer.

(19) Context: A and B taste ice-cream X for the first time. Both enjoy it and can tell the same about each other, too. A to B:

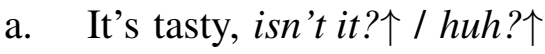
b. B: Yup.
c. B: No.

\footnotetext{
${ }^{3}$ If the speaker's commitment is about the addressee's commitment, one could argue that it is, after all, a dependent commitment, since it would change whenever the addressee would change their commitment. However, this would be triggered by a change of facts, which would also trigger a revision of independent commitments of any rational agent.
} 
If $\mathrm{B}$ confirms, both $p=$ 'ice-cream $\mathrm{X}$ is tasty' and $q=$ 'the addressee is a source for $p$ ' become grounded. If B disagrees, however, only $p$ gets rejected, but not $q$. In order to reject $q$, it has to be addressed explicitly, for example by "No, actually I just enjoyed the cherry on top, but the ice-cream itself is terrible". The fact that $q$ is not canceled by an answer like (19-c) alone supports the claim that $q$ is a presupposition.

This concludes the survey of pragmatic contexts which help characterize the bias profile of utterances with source tags. ${ }^{4}$

4. Source tags on the conversational scoreboard. In this section, I model the change in the context that utterances with source tags bring about. Based on the bias profile of huh?, eh? and $m i$ ? described by different contexts, I propose that when hosted by a declarative anchor, these tags convey the following meaning:

(20) A tag question $\phi$ consisting of a declarative anchor denoting a proposition $p$ and a source tag conveys that

a. $\quad q=$ the addressee is a source for $p$, and

b. that the speaker is a source for $q$.

To represent the change in the context that source tags bring about, I use a conversational scoreboard model building on Gunlogson (2008), Farkas \& Bruce (2010), Farkas \& Roelofsen (2012), and Malamud \& Stephenson (2015). The model keeps track of discourse participants such as the speaker $(S p k r)$ and the addressee $(A d d r)^{5}$; it marks whether a commitment to a proposition $p$ is a dependent one, updating the discourse commitment set of an interlocutor (CS) or an independent one, updating their source set (SS); it marks whether a commitment to $p$ is an actual one or only a conditional or projected commitment (Gunlogson 2008; Farkas \& Roelofsen 2012), which becomes an actual commitment upon acceptance by the addressee; it keeps track of the issues raised during the dialogue on the Table; and it keeps track of the common ground (CG). A blank conversational scoreboard is shown in Table 1.

(21) Model of discourse context

a. Discourse participants: $S p k r, A d d r$

b. Commitment set vs. source set:

i. $\mathrm{CS}_{x}$ : a set of possible worlds $w$ such that all of participant $x$ 's commitments are true in $w$

ii. $\mathrm{SS}_{x}$ : the source set or a set of sourced commitments of $x$ : a set of possible worlds $w$ such that all of $x$ 's independent commitments are true in $w$

c. Actual vs. projected commitments:

i. $c s_{x} / s s_{x}$ : actual commitments

ii. $c s_{x} * / s s_{x} *$ : projected commitments: propositions that will become commitments upon acceptance

\footnotetext{
${ }^{4}$ The examples given in this section and the account I give about their meaning in the next section are based on introspective judgments of native speakers of North American English, Italian and Hungarian. While this is a good way to make initial observations about any understudied linguistic phenomenon, I am aware of the fact that working with linguistic judgments has its own limitations. The variability of judgments observed in some of the above cases calls for a more systematic and indirect way of testing the claims made in this paper, which I leave for future research.

${ }^{5}$ For the sake of simplicity, I assume there to be only one addressee, because the number of addressees is not relevant for the present discussion.
} 
d. Table: a stack of issues raised during the conversation

e. Common ground:

(i) $\quad c g$ : the common ground between two speakers $x$ and $y$ is a set of propositions that are mutually believed to be commitments of both $x$ and $y$.

(ii) $c g^{*}$ : projected common ground, the next step in the development of the common ground, depending on the acceptance of a current proposal.

\begin{tabular}{|l|l|l|l|}
\hline \multicolumn{4}{|l|}{ Conversational Scoreboard } \\
\hline Discourse commitments & \multicolumn{2}{l|}{ Sourced commitments } \\
\hline $\mathrm{CS}_{S p k r}$ & $\mathrm{CS}_{S p k r} *$ & $\mathrm{SS}_{S p k r}$ & $\mathrm{SS}_{S p k r} *$ \\
\hline\{\} & \{\} & \{\} & \{\} \\
\hline $\mathrm{CS}_{A d d r}$ & $\mathrm{CS}_{A d d r} *$ & $\mathrm{SS}_{A d d r}$ & $\mathrm{SS}_{A d d r} *$ \\
\hline\{\} & \{\} & \{\} & \{\} \\
\hline Table & $\langle\{\}\rangle$ & \multicolumn{2}{|l|}{} \\
\hline $\mathrm{CG}$ & \{\} & \multicolumn{3}{|l}{} \\
\hline $\mathrm{CG}^{*}$ & \{\} & \multicolumn{3}{|l|}{} \\
\hline
\end{tabular}

Table 1. Blank conversational scoreboard.

I now compare tag questions attributing epistemic authority to the addressee, acknowledgmenteliciting tag questions conveying speaker commitment to $p$, and source tags. A tag question that attributes epistemic authority to the addressee, such as same polarity tag questions in English (Malamud \& Stephenson 2015; Farkas \& Roelofsen 2017), the invariable tag sì? in Italian (Servidio 2014), or Hungarian utterance-final ugye? with a rising intonation (Molnár 2018, 2019) brings about the following changes on the conversational scoreboard.

(22) Context: B is eating ice-cream X, which A has not tried yet. A to B:

a. It's tasty, is it?

b. È buono, sì?

c. Finom, ugye?

In (22), the speaker tentatively attributes independent commitment $p=$ 'ice-cream $\mathrm{X}$ is tasty' to the addressee, hence, $p$ is put in the addressee's projected source set ( $\left.\mathrm{SS}_{A d d r}{ }^{*}\right)$. In addition, it also updates the Addressee's projected discourse commitments $\left(\mathrm{CS}_{A d d r}{ }^{*}\right)$, because by Gunlogson's definition, the source set of an interlocutor $x$ is a subset of the commitment set of $x$. Finally, $p$ is also placed on the Table. The effect of such tag questions on the context is shown on Table 2.

Other tag questions can convey a higher level of speaker certainty, and their function is merely to elicit acknowledgment or participation in the discourse. The English reverse polarity tag questions with a falling tune (Farkas \& Roelofsen 2017), as well as Italian no? (Servidio 2014) and Hungarian ugye? (Molnár 2018) can serve such a purpose.

(23) Context: A and B both are eating ice-cream X. A enjoys its taste but doesn't know what B thinks of it, however, A expects that B would like it, too. A to B:
a. It's tasty, isn't it? $\downarrow$
b. È buono, no?
c. Finom, ugye? 


\begin{tabular}{|c|c|c|c|}
\hline \multicolumn{4}{|c|}{ Conversational Scoreboard } \\
\hline \multicolumn{2}{|c|}{ Discourse commitments } & \multicolumn{2}{|c|}{ Sourced commitments } \\
\hline $\mathrm{CS}_{S p k r}$ & $\mathrm{CS}_{S p k r} *$ & $\mathrm{SS}_{S p k r}$ & $\mathrm{SS}_{S p k r} *$ \\
\hline\{\} & \{\} & \{\} & \{\} \\
\hline $\mathrm{CS}_{A d d r}$ & $\mathrm{CS}_{A d d r} *$ & $\mathrm{SS}_{A d d r}$ & $\mathrm{SS}_{A d d r} *$ \\
\hline\{\} & $\{p\}$ & \{\} & $\{p\}$ \\
\hline Table & \multicolumn{3}{|l|}{$\langle\{p\}\rangle$} \\
\hline CG & \multicolumn{3}{|l|}{} \\
\hline $\mathrm{CG}^{*}$ & \multicolumn{3}{|l|}{$p$} \\
\hline
\end{tabular}

Table 2. The conversational scoreboard after pronouncing the tag question in (22)

Their effect on the discourse context is shown in Table 3.

\begin{tabular}{|l|l|l|l|}
\hline \multicolumn{4}{|l|}{ Conversational Scoreboard } \\
\hline Discourse commitments & \multicolumn{2}{l|}{ Sourced commitments } \\
\hline $\mathrm{CS}_{\text {Spkr }}$ & $\mathrm{CS}_{S p k r} *$ & $\mathrm{SS}_{\text {Spkr }}$ & $\mathrm{SS}_{\text {Spkr }} *$ \\
\hline$\{p\}$ & $\{p\}$ & $\{p\}$ & $\{p\}$ \\
\hline $\mathrm{CS}_{A d d r}$ & $\mathrm{CS}_{A d d r} *$ & $\mathrm{SS}_{A d d r}$ & $\mathrm{SS}_{\text {Addr }} *$ \\
\hline\{\} & $\{p\}$ & \{\} & $\{p\}$ \\
\hline Table & $\langle\{p\}\rangle$ & & \\
\hline $\mathrm{CG}$ & \{\} & \multicolumn{2}{l|}{} \\
\hline $\mathrm{CG}^{*}$ & $\{p\}$ & \multicolumn{3}{|l|}{} \\
\hline
\end{tabular}

Table 3. The conversational scoreboard after pronouncing the tag question in (23)

The effect of source tags on the context is different from both previous groups of question tags, as they manipulate two propositions: the proposition conveyed by the anchor of the tag question $(p)$, and a meta-conversational proposition $(q)$ with the content 'the addressee is a source for $p$ in the current dialogue $d^{\prime}$.

A source tag adds $p$ to the addressee's projected source set, and commits the speaker to $q$ as a source. Adding a proposition to the source set automatically adds a proposition to the commitment set (Gunlogson 2008), so $p$ is also added to $\mathrm{CS}_{A d d r}{ }^{*}$, and $q$ is also added to $\mathrm{CS}_{S p k r}$ and to $\mathrm{CS}_{S p k r} *$. Note that only $p$ is added to the Table, as only $p$ is associated with a syntactic object, but not $q$ (Farkas \& Bruce 2010). Proposition $q$ is a pragmatic presupposition, hence it is not at-issue, and cannot be referred back to by response particles (cf. example (19)). It is therefore added to the speaker's commitment sets and to the projected common ground, without making it to the Table. The effect of a source tag on the context is shown in Table 4. If the utterance with the source tag gets a confirmative response, $q$ becomes common ground. If the addressee gives a negative response, $q$ will not be common ground but will still be present in the speaker's commitment sets, from which it may or may not later be removed by the speaker. The two outcomes are shown in Table 5 . 


\begin{tabular}{|l|l|l|l|}
\hline \multicolumn{4}{|l|}{ Conversational Scoreboard } \\
\hline Discourse commitments & \multicolumn{2}{l|}{ Sourced commitments } \\
\hline $\mathrm{CS}_{\text {Spkr }}$ & $\mathrm{CS}_{\text {Spkr }}{ }^{*}$ & $\mathrm{SS}_{\text {Spkr }}$ & $\mathrm{SS}_{\text {Spkr }}$ \\
\hline$\{q\}$ & $\{q\}$ & $\{q\}$ & $\{q\}$ \\
\hline $\mathrm{CS}_{\text {Addr }}$ & $\mathrm{CS}_{A d d r} *$ & $\mathrm{SS}_{\text {Addr }}$ & $\mathrm{SS}_{\text {Addr }} *$ \\
\hline\{\} & $\{p\}$ & \{\} & $\{p\}$ \\
\hline Table & $\langle\{p\}\rangle$ & & \\
\hline CG & \{\} & & \\
\hline CG $^{*}$ & $\{p, q\}$ & \multicolumn{2}{|l}{} \\
\hline
\end{tabular}

Table 4. The conversational scoreboard after an utterance with a source tag pronounced by the speaker $(S p k r)$, where $p=$ the proposition conveyed by the anchor, and $q=$ 'the addressee is a source for $p$ (in the current dialogue $d$ )'.

\begin{tabular}{|c|c|c|c|}
\hline \multicolumn{4}{|c|}{ Conversational Scoreboard } \\
\hline \multicolumn{2}{|c|}{ Discourse commitments } & \multicolumn{2}{|c|}{ Sourced commitments } \\
\hline $\mathrm{CS}_{S p k r}$ & $\mathrm{CS}_{S p k r}{ }^{*}$ & $\mathrm{SS}_{S p k r}$ & $\mathrm{SS}_{S p k r}{ }^{*}$ \\
\hline\{\} & \{\} & \{\} & \{\} \\
\hline $\mathrm{CS}_{A d d r}$ & $\mathrm{CS}_{A d d r}{ }^{*}$ & $\mathrm{SS}_{A d d r}$ & $\mathrm{SS}_{\text {Addr }}{ }^{*}$ \\
\hline\{\} & \{\} & \{\} & \{\} \\
\hline Table & \multicolumn{3}{|l|}{$\langle\{\}\rangle$} \\
\hline CG & \multicolumn{3}{|l|}{$p, q$} \\
\hline $\mathrm{CG}^{*}$ & \multicolumn{3}{|l|}{} \\
\hline
\end{tabular}

\begin{tabular}{|l|l|l|l|}
\hline \multicolumn{3}{|l|}{ Conversational Scoreboard } \\
\hline Discourse commitments & \multicolumn{2}{l|}{ Sourced commitments } \\
\hline $\mathrm{CS}_{S p k r}$ & $\mathrm{CS}_{S p k r} *$ & $\mathrm{SS}_{S p k r}$ & $\mathrm{SS}_{S p k r} *$ \\
\hline$\{q\}$ & \{\} & $\{q\}$ & \{\} \\
\hline $\mathrm{CS}_{\text {Addr }}$ & $\mathrm{CS}_{A d d r} *$ & $\mathrm{SS}_{A d d r}$ & $\mathrm{SS}_{\text {Addr }} *$ \\
\hline\{\} & \{\} & \{\} & \{\} \\
\hline Table & $\langle\{\}\rangle$ & \multicolumn{2}{|l|}{} \\
\hline $\mathrm{CG}$ & \{\} & \multicolumn{4}{|l}{} \\
\hline $\mathrm{CG}^{*}$ & \{\} & \multicolumn{4}{|l|}{} \\
\hline
\end{tabular}

Table 5. The conversational scoreboard after the addressee's answer to an utterance with a source tag. The table on the left side shows the context after a confirmative answer, and the table on the right side, the context after a negative answer.

5. Remaining issues. The present paper characterizes the bias profile of source tags by means of constructed examples. In doing so, it offers a first look at source tags, as they are used with declarative anchors in three languages. However, there is more to say about them, and in this section, I raise some of the issues that remain open, all of which are left for future research.

5.1. Contextual Bias. It has been proposed that speaker bias should be classified into bias originating from the speaker's expectation and bias originating from the context of discourse (Büring \& Gunlogson 2000; Sudo 2013; Northrup 2014; Gärtner \& Gyuris 2017). In the contexts where source tags are acceptable, contextual evidence indeed plays an important role. It is not clear, however, whether or not what I have called a speaker presupposition here is in fact contextual bias. The answer to this question depends on whether source tags are felicitous in a context without 'contextual evidence', such as the one in (24), a modified version of (18).

(24) Context: B and C have tasted ice-cream $\mathrm{X}$, and B found it very tasty. Later on, $\mathrm{C}$ then tells this to A, who herself has tried ice-cream $\mathrm{X}$ and liked it. Even later, A meets B:

A: I heard you tried ice-cream X. So did I, and I like it a lot.

a. It was tasty, wasn't it? / ?huh?

b. Era buono, no? / ?eh? (Italian)

c. Finom volt, ugye? / ?mi? (Hungarian)

In this context, the speaker's independent commitment is based on some evidence from the 
past, which is not directly available in discourse. If A can continue her turn by (24-a)-(24-c), it means that the speaker bias in source tags is not due to contextual evidence; but if A cannot use source tags in this context, it suggests that source tags are sensitive to contextual evidence. This seems to be a question that calls for empirical observations, but for now it has to remain open.

5.2. Evidentiality. While English huh? convey evidential meaning according to Norrick (1995), this does not qualify source tags as evidentials, because the core meaning of evidentials is the source of evidence (Aikhenvald 2004). Even if this is the case with source tags historically, this meaning is not available to speakers, so at this point there is no reason to assume that source tags encode any restrictions about how the speaker or the addressee became independently committed to the relevant proposition. Rather, source tags constitute what is better labeled as an evidentiality strategy, which Aikhenvald defines as "categories and forms which acquire secondary meanings somehow related with information source".

5.3. Cognates. We find cognates in the realm of tag questions across languages in the IndoEuropean family. Besides Italian, the tag eh? can be found in Spanish (García Vizcaíno 2005), Catalan (Castroviejo 2018), and in Canadian English (Gold \& Tremblay 2006; Wiltschko et al. 2018). Further possible cognates are hein? in Brazilian Portuguese and Canadian and European French, and possibly Dutch hè (Tulling 2014). Information about similarities in the semantic-pragmatic meaning of these tags across languages could potentially support the analysis offered here.

5.4. Multiple Functions. Question tags are known to have a wide range of functions in discourse and it is an important desideratum in linguistic research to provide an account, if possible, from which all the apparently different functions can be derived.

One other function that huh?,eh? and $m i$ ? share is that they can elicit a repetition of the previous utterance. The register of such an utterance is very informal.
a. A: Did anyone call me?
b. B: Huh? (What was that?) / Eh? / Mi?
c. A: Did anyone call me?

Source tags can also modify wh-questions, in which case they become biased questions with a provocative/disapproving tone. In this use, too, they seem to have an have answer-eliciting function.

(26) a. Why did you eat all the chocolate, huh?!

b. $\quad$ Miért etted meg az összes csokit, $m i$ ?!

Besides these functions, North American English huh can also be used with falling intonation. In this form, it serves as mirative particles according to Kraus (2019).

a. Jeff made pizza dough this morning.

b. Huh. I thought he didn't know how to cook.

(Kraus 2019; (1b))

This fact raises the question of whether huh? as a question tag also has a mirative meaning component. If it has a mirative component, it is likely part of the speaker presupposition, but this question, too, is left open here.

Italian $e h$ ? can modify various speech acts, not just ones that have an assertive illocu- 
tionary point but also essentially hearer-directed speech acts such as the one shown in (28), which has an imperative anchor. This utterance can be said by a parent who is leaving their baby with the baby sitter.

(28) Fa il bravo, eh?

'Come on, do your best!'

In sum, the tags huh?, eh? and mi? each have further uses in discourse that they do not necessarily share across languages. This paper described their use as source tags only, but these additional functions call for a comprehensive analysis. Ultimately, it is desirable to give a unified account of these tags, from which their different discourse functions be derived.

5.5. SARCASM AND IMPOLITENESS. Source tags in all the three languages looked at here are more prone to convey irony compared to basic tag questions. Compare the tag questions in (7)-(9), repeated here in (29), which shows infelicitous forms of a first question at a courtroom hearing.

a. You are a member of the Communist Party, \#aren't you? / \#huh?

b. Lei è membro del Partito Comunista, \#no? / \#eh?

c. Ön tagja a Kommunista Pártnak, \#ugye? / \#mi?

While both tags add a sarcastic flavor to the utterance, contributing thereby to their unacceptability in a context which is not supposed to convey non-neutral affective stance, huh?, eh? and $m i$ ? can amplify sarcasm, more so than weren't you?, no?, and ugye?. I speculate that this is made possible by the speaker presupposition which presents the speaker as being independently committed to the addressee's sourcehood for $p$. Since sourcehood is often (although not obligatorily) tied to direct perception, presupposing the speaker's sourcehood along with the tag question can result in the message of 'regardless of your answer, I can tell that you are a source for $p$ '. What gives rise to sarcasm is the contrast between the inquiry about a certain matter (whether the addressee is a member of the Communist Party), and a presupposition that resolves the same issue (the presupposition that the addressee is a member of the Communist Party). For a similar reason, this speaker presupposition also gives rise to impoliteness effects. It is hypothesized that the more direct access to a certain piece of information one attributes to their addressee, the less polite the utterance will be (San Roque et al. 2017).

6. Conclusion. In this paper, I argued that when hosted by a declarative anchor, tags like English huh? (with rising intonation), Italian $e h$ ?, and Hungarian mi? commit the speaker and the addressee as sources for different propositions. Therefore I named such tags as source tags. Due to the presence of source tags, the addressee is perceived by the speaker as a source for $p$, the proposition conveyed by the anchor, and the speaker presupposes that she is a source for the proposition that the addressee is a source for $p$ in the same dialogue. Source tags are special in that they attribute a commitment both to the speaker and the addressee, and in that they are used as part of an evidentiality strategy. The analysis provided in this paper is a first look at their perhaps most salient use as modifiers of assertive speech acts.

\section{References}

Aikhenvald, Alexandra Y. 2004. Evidentiality. Oxford: Oxford University Press. Asher, Nicholas \& Brian Reese. 2007. Intonation and discourse: Biased questions. In Shinichiro 
Ishihara, Stefanie Jannedy \& Anne Schwarz (eds.), Interdisciplinary studies on information structure, 1-38. Potsdam: Universitätsverlag Potsdam.

Büring, Daniel \& Christine Gunlogson. 2000. Aren't positive and negative polar questions the same? Ms.

Castroviejo, Elena. 2018. On question tags and confirmation requests, Talk presented at GLOW 41, Budapest.

Cheung, Lawrence Yam-Leung. 2009. Negative wh-construction and its semantic properties. Journal of East Asian Linguistics 18. 297-321. https://doi.org/10.1007/ s10831-009-9051-2.

Eckardt, Regine \& Qi Yu. 2020. German bloss questions as extreme ignorance questions. Linguistica Brunensia 68. 7-22. https://doi.org/10.5817/LB2020-1-2.

Egg, Markus. 2013. Discourse particles, common ground, and felicity conditions. In Daniel Gutzmann \& Hans-Martin Gärtner (eds.), Beyond expressives: Explorations in use-conditional meaning, 125-150. Leiden: Brill.

Farkas, Donka F. \& Kim B. Bruce. 2010. On reacting to assertions and polar questions. Journal of Semantics 27. 81-118. https://doi.org/10.1093/jos/ffp010.

Farkas, Donka F. \& Floris Roelofsen. 2012. Polar initiatives and polarity particle responses in an inquisitive discourse model. Ms, UC Santa Cruz.

Farkas, Donka F. \& Floris Roelofsen. 2017. Division of labor in the interpretation of declaratives and interrogatives. Journal of Semantics 34. 237-289. https://doi.org/10. 1093/jos/ffw012.

García Vizcaíno, María J. 2005. El uso de los apéndices modalizadores no? y eh? In Lotfi Sayahi \& Maurice Westmoreland (eds.), Proceedings of the 2nd Workshop on Spanish Sociolinguistics, 89-101. Somerville, MA: Cascadilla.

Giorgi, Alessandra. 2018. Ma non era rosso? (But wasn't it red?) On counter-expectational questions in Italian. In Lori Repetti \& Francisco Ordóñez (eds.), Romance languages and linguistic theory 14, 69-84. Amsterdam/Philadelphia: John Benjamins.

Gold, Elaine \& Mireille Tremblay. 2006. Eh? and hein?: Discourse particles or national icons? Canadian Journal of Linguistics 51. 247-263. https://doi.org/10.1017/ S0008413100004096.

Grice, H. P. 1975. Logic and Conversation. In Peter Cole \& Jerry L. Morgan (eds.), Syntax and Semantics III, 41-58. New York: Academic Press.

Gunlogson, Christine. 2003. True to form: Rising and falling declaratives as questions in English. New York: Routledge.

Gunlogson, Christine. 2008. A question of commitment. Belgian Journal of Linguistics 22. 101136. https://doi.org/10.1075/bj1.22.06gun.

Gyuris, Beáta. 2009. Sentence-types, discourse particles and intonation in Hungarian. In Arndt Riester \& Torgrim Solstad (eds.), Proceedings of Sinn und Bedeutung 13, 157-171.

Gärtner, Hans-Martin \& Beáta Gyuris. 2017. On delimiting the space of bias profiles for polar interrogatives. Linguistische Berichte 251. 293-316.

Ippolito, Michela. 2019. Gestures as markers of non-canonical questions. In Julian J. Schlöder, Dean McHugh \& Floris Roelofsen (eds.), Proceedings of the 22nd Amsterdam Colloquium, 574-583. Amsterdam: ILLC.

Kiss, Angelika. 2017. Meta-conversational since when-questions and the common ground. In Volha Petukhova \& Ye Tian (eds.), Proceedings of the 21st Workshop on the Semantics and Pragmatics of Dialogue, 38-47. Saarbrücken: SEMDIAL.

Kiss, Angelika. 2020. Whatever can be meant can be echoed: A comparison of since when questions and echo declarative questions. In Monika Kirner-Ludwig (ed.), Fresh perspectives on major issues in pragmatics. London: Routledge.

Kraus, Kelsey. 2019. Intonation and expectation: English mirative contours and particles. Proceedings of Sinn und Bedeutung 23. 19-36. https://doi.org/10.18148/sub/2019.v23i2.596. 
Ladd, D. Robert. 1981. A first look at the semantics and pragmatics of negative questions and tag questions. Proceedings of Chicago Linguistic Society (CLS) 17. 164-171.

Malamud, Sophia \& Tamina Stephenson. 2015. Three ways to avoid commitment: Declarative force modifiers in the conversational scoreboard. Journal of Semantics 32. 275-311. https://doi.org/10.1093/jos/ffu002.

Molnár, Cecília. 2018. Speciális kérdések? - Az ugye partikulát tartalmazó megnyilatkozások formája és használata. [Special questions? - The form and use of utterances containing the particle ugye]. Budapest: Eötvös Loránd University dissertation.

Molnár, Cecília. 2019. Hungarian ugye is a tag, isn’t it? In Beáta Gyuris, Katalin Mády, \& Gábor Recski (eds.), $K+K=120$. Festschrift for László Kálmán and András Kornai on the occasion of their 60th birthdays, 399-424. Budapest: MTA Research Institute for Linguistics.

Norrick, Neal R. 1995. Hunh-tags and evidentiality in conversation. Journal of Pragmatics 23. 687-692. https://doi.org/10.1016/0378-2166(94)00045-G.

Northrup, Oliver. 2014. Grounds for commitment. Santa Cruz, CA: University of California dissertation.

Poschmann, Claudia. 2008. All declarative questions are attributive? Belgian Journal of Linguistics 22. 247-269. https://doi.org/10.1075/bj1.22.12pos.

Reese, Brian. 2007. Bias in questions. Austin, TX: The University of Texas dissertation.

Romero, Maribel \& Chung-Hye Han. 2004. On negative yes/no questions. Linguistics and Philosophy 27. 609-658. https://doi.org/10.1023/B:LING.0000033850.15705.94.

San Roque, Lily, Simeon Floyd \& Elisabeth Norcliffe. 2017. Evidentiality and interrogativity. Lingua 186-187. 120-143. https://doi.org/10.1016/j.lingua.2014.11.003.

Servidio, Emilio. 2014. Polarity particles in interrogative tags. In Carla Contemori \& Lena Dal Pozzo (eds.), Inquiries into linguistic theory and language acquisition. Papers offered to Adriana Belletti, 198-215. Siena, IT: CISCL PRESS.

Stalnaker, Robert. 1974. Pragmatic presuppositions. In Milton K. Munitz \& Peter K. Unger (eds.), Semantics and philosophy. New York: New York University Press.

Sudo, Yasutada. 2013. Biased polar questions in English and Japanese. In Hans-Martin Gärtner \& Daniel Gutzmann (eds.), Beyond expressives: Explorations in use-conditional meaning, 275295. Leiden: Brill.

Tulling, Maxime. 2014. Divide and conquer: Split CP hypothesis in rhetorical questions, the case of sentence-final particles in rhetorical questions. Utrecht University B.A. thesis.

Wiltschko, Martina, Alex D’Arcy \& Derek Denis. 2018. Deconstructing variation in pragmatic function: A transdisciplinary case study. Language in Society 47. 569-599. https://doi.org/10.1017/S004740451800057X. 